\title{
CRIATIVIDADE NO COTIDIANO DE JOVENS: O LUGAR DA ESCOLA E DA EXPERIÊNCIA
}

Alcimar Enéas Rocha Trancoso ${ }^{\mathrm{I}}$

Rosemeire Reis II

I Universidade Federal de Alagoas (Ufal), Maceió (AL), Brasil; osocnart@gmail.com

II Universidade Federal de Alagoas (Ufal), Maceió (AL), Brasil; reisroseufal@gmail.com

\section{Resumo}

Analisamos em que medida a experiência escolar e as manifestações criativas cotidianas se relacionam. Realizamos pesquisa qualitativa, sócio-histórica, utilizando entrevistas semiestruturadas com sete jovens estudantes, analisadas a partir dos núcleos de significação estabelecidos. A experiência social, de princípios heterogêneos, foi compreendida como forma de designar as condutas, produzidas a partir da combinação de distintas lógicas de ação. Os jovens pesquisados se consideraram criativos. A experiência escolar se vinculava à criatividade na vida cotidiana na medida em que se conectavam nas redes de espaços que se estabeleciam na experiência juvenil de cada um. A escola, e o que ela representava para eles, não era interpretada como locus significativo para a experiência dos atores.

\section{CRIATIVIDADE • ESCOLA • JUVENTUDE • EXPERIÊNCIA SOCIAL}

\section{CREATIVITY IN THE DAILY LIVES OF YOUNG PEOPLE: THE PLACE OF SCHOOL AND EXPERIENCE}

\section{Abstract}

Creativity and school mark the daily lives of an expressive youth segment. We analyze the extent to which school experience and everyday creative manifestations are related. We conducted qualitative, socio-historical research, using semi-structured interviews with seven young students, analyzed from the established meaning nuclei. The social experience, of heterogeneous principles, was understood as a way of designating the behaviors, produced from the combination of different logics action. The young people surveyed considered themselves creative. The school experience was linked to creativity in everyday life insofar as they were connected in the networks of spaces that were established in the youth experience of each one. The school, and what it represented to them, was not interpreted as a significant locus for the actors' experience. 


\section{LA CREATIVIDAD EN LA VIDA COTIDIANA DE LOS JÓVENES: EL LUGAR DE LA ESCUELA Y DE LA EXPERIENCIA}

\section{Resumen}

Analizamos el grado en que la experiencia escolar y las manifestaciones creativas cotidianas están relacionadas. Se realizó una investigación cualitativa, socio histórica, utilizando entrevistas semiestructuradas con siete jóvenes estudiantes, analizados a partir de los núcleos de significado establecidos. La experiencia social, de principios heterogéneos, fue entendida como una forma de designar las conductas, producidas a partir de la combinación de diferentes lógicas de acción. Los jóvenes encuestados se consideraban creativos. La experiencia escolar estuvo ligada a la creatividad en la vida cotidiana ya que se conectaron en las redes de espacios que se establecieron en la experiencia juvenil de cada uno. La escuela, y lo que representaba para ellos, no era interpretada como locus significativo para la experiencia de los actores.

CREATIVIDAD • ESCUELA • JUVENTUD • EXPERIENCIA SOCIAL

\section{LA CRÉATIVITÉ DANS LE QUOTIDIEN DES JEUNES : LE RÔLE DE L'ÉCOLE ET DE L'EXPÉRIENCE}

\section{Résumé}

Ce travail analyse dans quelle mesure l'expérience scolaire et les manifestations créatives du quotidien sont liées. Une recherche qualitative et socio-historique a été réalisée à l'aide d'entretiens semi-directifs menés auprès de sept jeunes élèves. Les résultats ont été analysés à partir des noyaux de sens qui s'en sont dégagés. L'expérience sociale, aux principes hétérogènes, a été saisie comme une manière de désigner des comportements, produits à partir de la combinaison de différentes logiques d'action. Les jeunes interrogés se sont tous considérés comme créatifs. L’expérience scolaire est apparue liée à la créativité dans la vie quotidienne dans la mesure où les élèves y ont reconnu les réseaux d'espaces déjà présents dans leur propre expérience juvénile. L'école, et ce qu'elle représentait pour eux, n’a pas été interprétée comme un locus significatif pour l'expérience des acteurs.

CRÉATIVITÉ • ÉCOLE •JEUNESSE • EXPÉRIENCE SOCIALE 

cotidiano, e experiência escolar na vida de jovens estudantes do último ano do ensino médio, buscando caracterizar as desconexões/conexões por eles formadas.

Juventude e criatividade atraem a atenção do senso comum e da academia. Por um lado, há recorrência nos discursos a respeito de exigência contemporânea quase tácita de criatividade, especialmente da juventude, em particular como requisito para disputa e inserção no mundo do trabalho (Veloso, 2010). Criatividade como evento que se transforma em produto, esforço de integração dos sujeitos ao status quo de uma sociedade predominantemente capitalista. Tal perspectiva de criatividade é oposta à preconizada neste artigo. Mitjáns Martínez (1997, p. 53), cujo ponto de vista coadunamos, concebe a atração exercida pelo tema nos diversos campos - essa exigência e perspectiva espetacular de criatividade - como algo historicamente condicionado pelas imposições "da sociedade moderna, o crescente avanço da ciência e da técnica e o interesse pelo desenvolvimento das potencialidades humanas". De uma forma ou de outra, os sujeitos são desafiados a criar, mobilizados a partir dos seus processos de apropriação ou motivados - como forma de resistência ou não - pelas pressões normalizadoras nos distintos espaços de socialização.

Além disso, as demandas da juventude, sua formação como sujeitos criativos, suas escolhas, seu presente e seu futuro são assuntos efervescentes. Em parte, por se entender que as mudanças culturais dos tempos atuais podem ser percebidas com maior visibilidade na juventude do que em outros grupos sociais, funcionando como uma síntese da sociedade. $\mathrm{O}$ aspecto característico da contemporaneidade de valorização do tempo presente a converte num modelo cultural. Como escrevem Leão e Carmo (2014, p. 20), “. . . neste mundo, o presente tem grande força, e a juventude tem um lugar especial, pelo menos do ponto de vista dos ícones culturais, estéticos e midiáticos. Todos querem se vestir, se comportar e ter um corpo juvenil. ..", talvez por verem nela, ainda que em perspectiva, o vigor, a capacidade operativa e intelectual de produzir, explorar e experimentar sentidos.

Mas qual a relação da juventude com a criatividade? Direta, na medida em que a criatividade é entendida aqui como sempre presente na nossa relação com o mundo. Criamos, como escreve Ostrower (2001), não por gosto, prazer, mas por precisão, como proposição ou resposta ao mundo, não como algo natural ou espontâneo, mas originado no trabalho, atividade humana que transforma a realidade e o próprio homem. Também, por compreendermos o desenvolvimento humano como processo sócio-histórico: à medida que se desenvolve, e as estruturas da personalidade vão se formando, a pessoa vai aumentando sua capacidade criativa em movimento concomitante ao acúmulo de experiências e ao desenvolvimento da racionalidade, em uma relação direta com a capacidade e o exercício da imaginação, que, no processo de desenvolvimento, passa de um vínculo quase exclusivo com a fantasia, na infância, para uma relação, também frutífera, com a racionalidade, tendo na juventude o seu ápice (Vigotski, 2009).

Esta ação - viver, estar no mundo cotidianamente travando com ele uma relação - para a maioria dos jovens brasileiros, ${ }^{1}$ em alguma medida, também se relaciona com o estar na escola. Pelo menos dois fatores têm contribuído historicamente para isso. A vigente Constituição Federal (1988), no seu artigo 208, ao intencionar a progressiva universalização do acesso à escola pública até o ensino médio, desencadeia um movimento nos distintos entes federativos de massificação da educação básica.

1 De acordo com o Instituto Brasileiro de Geografia e Estatística (IBGE), o número médio de anos de estudo para a população de 15 a 17 anos e 18 a 29 anos de idade em 2019, respectivamente, era de 9,2 e 11,4 anos e a taxa de escolarização entre as pessoas de 15 a 17 anos em 2019 era de 89,2\% (https://sidra.ibge.gov.br/pesquisa/pnadca/tabelas). 
Também, a Lei n. 12.852/2013, que institui o Estatuto da Juventude no Brasil, ao considerar como jovens pessoas entre 15 e 29 anos de idade, reforça, ainda que em tese, a relação do jovem com a escola: frequentarão, no mínimo, o ensino médio e a graduação.

Essa prática disseminada e protegida pela lei contribui para que o ambiente, a cultura e a experiência escolar tenham importância significativa na sociedade hodierna, por ajudar a formar o jovem e uma opinião sobre ele e o fenômeno da juventude.

Não significa, no entanto, a defesa de que, no Brasil, a universalização do ensino médio entre os jovens ocorre de maneira linear, planejada, sem sobressaltos, retrocessos ou contradições. Em 2019, por exemplo, de acordo dados da Pesquisa Nacional por Amostra de Domicílios (Pnad), em torno de 9,8 milhões de pessoas de 14 a 29 anos estavam fora da escola, abandonaram sem completar o ensino médio, sendo que aproximadamente 5,04 milhões deixaram a escola entre 16 e 18 anos de idade (Instituto Brasileiro de Geografia e Estatística, s.d.), o que permite caracterizar a atual realidade de acesso à educação e permanência na escola mais como uma expansão do que universalização, "devido às altas porcentagens de jovens ainda fora da escola e a persistência de altos índices de evasão e reprovação" (Dayrell \& Jesus, 2016, p. 412).

Mas significa entender a sociedade contemporânea como escolarizada, estando a escola no centro de suas referências identificatórias, conforme abordado por Dallabrida (2004) e Sposito (2003), percebendo-a sob a orientação cultural hegemônica de que ir para a escola é mais que desejável, é uma obrigação legal sob pena de sanção. A massificação em curso, como afirma Leão (2018), não se faz acompanhada de uma equivalente melhoria, ampliação, adequação da estrutura escolar nem das condições de trabalho dos professores, que, em tese, apoiariam o sucesso dessa nova realidade.

Dessa forma, portanto, a escola assume um papel importante no processo de educação das novas gerações, colocando-se no rol dos principais espaços de socialização secundária pelos quais passam os sujeitos: "nas sociedades modernas, a escola é a instituição cuja função específica é formar as novas gerações para a vida social" (Leão \& Carmo, 2014, p. 37). Não ocupa o papel central na construção da condição juvenil, visto que múltiplos fatores estão presentes nesse processo de exposição complexa em espaços heterogêneos e concorrentes (Dayrell, 2007), mas tem um lugar importante na construção dessa condição juvenil, por ser um espaço-tempo em torno do qual se organizam experiências específicas e articuladas.

Mesmo os jovens que estão fora da escola, afastados por qualquer motivo ou que nunca se matricularam, têm sido alvo de preocupações e planos, materializados às vezes em políticas públicas, para sua inserção ou mitigação dos efeitos dessa exclusão, tidos como negativos.

O cotidiano das juventudes, portanto, está marcado pela criatividade como possibilidade e pela escola, seja por estarem nela como estudantes, seja pelo fato de a escola e o que flutua em seu entorno (taxa de sucesso, permanência, analfabetismo, formação para o trabalho, etc.) serem componentes dos distintos indicadores que avaliam a condição juvenil. Não buscamos neste texto refletir sobre questões relacionadas ao conteúdo escolar ou à escola como uma instituição complexa (Ezpeleta \& Rockwell, 1989), mas, tendo a escola como ambiente a partir do qual o jovem constrói uma experiência social específica, refletir sobre os efeitos desta experiência no seu agir criativo no cotidiano. Também não interrogamos a escola sobre sua estrutura para a criatividade ou a produção de espaços de criação (Biarnès, 2007), mas os jovens e seus discursos sobre as relações feitas entre suas ações criativas cotidianas e a experiência escolar.

\section{Criatividade, experiência escolar e cotidiano: categorias analíticas}

Além da concepção de juventude, vista como categoria social, definida a partir das relações estabelecidas social e historicamente, e, conforme se apresenta no Brasil, atravessada pela escolarização como realidade e parâmetro para análise da sua situação, o discurso dos jovens foi analisado a partir de três outras categorias postas em perspectiva: experiência escolar, criatividade e cotidiano. 
Discutimos experiência escolar tendo como pano de fundo o escopo epistemológico mais amplo da experiência social, que inclui pensar a socialização como "o duplo movimento pelo qual uma sociedade se dota de atores capazes de assegurar sua integração e de indivíduos, de sujeitos suscetíveis de produzir uma ação autônoma" (Dubet \& Martuccelli, 1997, p. 241), configurando uma tensão criadora. Tal experiência social é compreendida como forma de designar as condutas sociais das pessoas, organizadas por princípios heterogêneos e produzidas a partir da combinação de distintas lógicas de ação. A experiência escolar, tida como a forma pela qual os atores individuais ou coletivos combinam diversas lógicas de ação que estruturam o mundo escolar, integra-se ao quadro de experiências possíveis. Ela se dá em meio a tudo o que significa o mundo escolar: as atividades escolares dentro e fora da escola; as distintas mobilizações para o estudo e para estar na escola; as relações com os professores, colegas, família, amizades; e o impacto disso nas escolhas feitas, afetos, etc. Isso ocorre, em parte, por meio de um processo de apropriação daquilo que a escola propõe, seus conteúdos e suas dimensões enquanto parte de um sistema, perpassada por lógicas da ação - integração, estratégia e subjetivação.

Em sucinta abordagem, a integração representa o vínculo a um grupo de pares, uma philia, um grupo de iguais, com quem se dividem amizades, confidências e amores. Nessa lógica, o gostar da escola significa mais gostar "do mundo das afinidades eletivas que se desenvolvem nas fendas da organização escolar, os intervalos, os recreios, os cafés, os passeios, tudo o que, do ponto de vista deles, faz parte de uma formação da sua personalidade" (Dubet, 1994, p. 210). A ação estratégica vincula-se ao lidar com a escola como um mercado, com um produto específico - o diploma - que pode satisfazer a alguma necessidade futura relacionada ao mercado de trabalho. Na sala de aula, a turma quase sempre faz dela um ambiente onde se produzem alianças e conflitos. As matérias e o próprio estabelecimento escolar são avaliados e classificados em termos de prestígio, grau de dificuldade imposto aos alunos, percentual de alunos que conseguem acesso à universidade, etc., construindo uma hierarquia (Dubet \& Martuccelli, 1998).

Por fim, a lógica da subjetivação faz papel de árbitro entre as duas outras lógicas. A experiência é entendida como processo contínuo de constituir-se num devir dialético: ao mesmo tempo que se transforma, afirma um modo de ser. A subjetivação configura-se como uma espécie de síntese da articulação das distintas experiências construídas nos diferentes espaços nos quais as pessoas circulam, incluindo o escolar, perpassando as ações que abrangem os demais pressupostos envolvidos nos modos de agir.

A criatividade é entendida como algo próprio da atividade humana, imersa no contexto sócio-histórico, parte do mecanismo que engloba aprendizado e desenvolvimento, processamento, adaptação e superação do que se apresenta na existência humana (Vigotski, 2009). Não é vista como algo individualizado, característica compartimentada que se manifesta em algumas esferas da vida, algo quase à parte do sujeito que o toma ou que o deixa circunstancialmente. Refletimos sobre a criatividade expressa na vida cotidiana, integrada ao viver, presente nas ações que representam novidade e valor para determinado contexto (Mitjáns Martínez, 1997), mas, também, nas táticas que conformam a rede de uma antidisciplina (Certeau, 1998), uma resistência subversiva, contrapartidas a qualquer tipo de dominação ou regulação da vida que se apresenta de forma heterônoma.

A criatividade, portanto, está presente na nossa relação com o mundo, desde a mais tenra idade, sempre socialmente mediada (Ostrower, 2001), e, ao se vincular diretamente à execução de uma atividade, pode ser compreendida como prerrogativa humana, não no sentido de ser uma exclusividade em termos da produção estrita de algo, de adaptação ao meio ou de organização de determinada coletividade, mas sim relacionada ao fato de o ser humano fazer o movimento duplo de criar na mente, imaginar, conceber mentalmente o que se quer antes de executar. É engendrada num movimento dialético entre reprodução e criação: a reprodução liga-se intimamente à memória, a reproduzir meios de conduta anteriormente criados e elaborados ou ressuscitar marcas de impressões precedentes; a criação - atividades combinatórias ou criadoras - ocorre a partir da imaginação e resulta necessariamente na produção de novas imagens e ações (Vigotski, 2009). 
Por fim, o cotidiano é concebido como os espaços sociais onde jovens vivem, movem-se e expressam sua criatividade em meio às diversas lógicas da ação. Espaços que ajudam a criar, afetando-os e sendo afetados, onde o exercício da criatividade nos interessa: as práticas cotidianas das pessoas ditas comuns, perpassadas de ações criadoras, ocorrendo de maneira indiscriminada e, muitas vezes, sem pretensão, o que justifica a ideia de criatividade para além do evento, manifestada no espaço da produção integral da vida, do qual ninguém pode escapar, como refletem Agnes Heller (1994) e Michel de Certeau (1998).

Esses autores, partindo de bases filosóficas distintas - Karl Marx traduzido por Georg Lukács e Ludwig Wittgenstein respectivamente -, propõem uma abordagem do cotidiano - sua estruturação e sua invenção -, enfocando a possibilidade de sua transformação, no sentido de evidenciar as diferenças entre o instituído e o que se apreende ou se subjetiva. A vida de todo homem e do homem todo é uma paráfrase do que escreveu Heller (1994) sobre o cotidiano, mas cabe também para as percepções de Certeau (1998). Para Heller, tem relação com a ideia de que, ao nascer, encontra-se um cotidiano pronto e, independentemente do estágio de consciência histórica do indivíduo, ele é e permanece inserido neste cotidiano a princípio estranho, mas que depois a ele se integra. Certeau já faz suas análises considerando fática essa integração ao cotidiano, não a representando numa relação cega de consumo cultural, mas de produção de um modo de vida fundado nas táticas, formas inventadas de usar as normas, ferramentas e comportamentos, subvertendo a ordem em maior ou menor grau. Pela ação, pode-se exercer um papel transformador, seja pelas práticas (as artes de fazer), seja pela assimilação de um modo de vida e sua transformação pelo desenvolvimento de ações não cotidianas, mas que nascem nele e nele refletem transformando-o.

As perspectivas gerais expostas acima a respeito do cotidiano não são por si mesmas geradoras ou impeditivas da criatividade. Esta, como prerrogativa do sujeito, ocorre a partir dele e onde estiver, independentemente de ser oficial e formalmente fomentada, de fazer ou não parte das estratégias de espaços mais controlados, como a escola.

\section{Método}

Para dar conta da questão proposta, realizamos pesquisa ${ }^{2}$ qualitativa de abordagem sócio-histórica, considerando o ser humano constituído na relação social, configuração antecedente à apropriação pessoal, mas que é por ela retroalimentada e afetada, num processo dialógico constante (Molon, 2008).

O objeto de estudo requereu algumas definições procedimentais. Primeiro, o locus. Optamos, por conveniência operacional, trabalhar com jovens de uma só escola: estando em um só lugar facilitaria a abordagem e a recolha das narrativas. O estabelecimento específico foi definido pela aproximação que já havíamos estabelecido: uma escola da rede pública estadual de Alagoas, na cidade de Maceió, onde já vínhamos construindo vínculos de trabalho e afetivo com docentes e o corpo diretivo pela realização anterior de outras pesquisas e por já ter sido frequentada por familiares de um dos pesquisadores.

Nesta escola, buscamos jovens voluntários, estudantes do último ano do ensino médio do turno matutino, pela suposição de que, pelo maior tempo na escola, tivessem maior volume de experiência e melhor condição de expressá-la. Após inserções divulgando a proposta da pesquisa no início dos anos letivos 2016 e 2017, vinte e seis jovens se voluntariaram inicialmente. Treze desistiram no percurso. Dos demais, somente com sete (quatro mulheres e três homens; três de 2016 e quatro de 2017) conseguimos conversar pelo menos duas vezes, o que proporcionou maior densidade de narrativa para as análises e inferências a respeito das relações entre a experiência escolar, o cotidiano e a criação. As narrativas

2 Pesquisa de doutorado, submetida ao Comitê de Ética da Universidade Federal de Maceió, aprovada em 01/06/2016, de acordo parecer n. 1.568.563. 
dos outros seis jovens, fruto apenas da primeira entrevista, não foram utilizadas para esta análise pela incompletude do conteúdo produzido.

O corpus analítico foi composto por entrevistas semiestruturadas, aprofundadas e recorrentes, orientadas por roteiros distintos e complementares. Na primeira, além das apresentações e conversa sobre objetivos da pesquisa, foram abordados temas ligados ao cotidiano (ações costumeiramente desenvolvidas no dia a dia, as coisas que achava mais importante) e à escola (descrição e comentários sobre o cotidiano escolar, a mobilização para a escola e a relação família-escola).

$\mathrm{Na}$ segunda e demais entrevistas, ocorridas sempre após a transcrição e análise preliminar das anteriores, a caminhada no processo da pesquisa era rememorada, e as questões referentes às conversas anteriores eram esclarecidas e aprofundadas. Além disso, abordávamos novamente temas ligados ao cotidiano dos jovens, como na primeira conversa. Na sequência, conversávamos sobre criatividade, sua relação com as coisas do cotidiano e da escola, abordando as ações ocorridas na rotina descrita consideradas criativas ou não pelos jovens.

Também ocorreram conversas informais com os jovens durante os intervalos das aulas, discorrendo sobre assuntos das entrevistas e do cotidiano escolar daquele momento, registradas em caderno de campo. Quatro jovens ainda elaboraram inventários dos usos do tempo e criatividade, uma espécie de diário em que descreveram ações criativas desenvolvidas em determinado dia. Essa ferramenta e a forma de utilizá-la foram apresentadas a todos sempre no final da primeira entrevista. Os conteúdos dessas conversas informais e dos inventários também foram objeto das discussões sobre criatividade a partir da segunda entrevista. A rotina de visitas à escola para encontros com os jovens equivaleu a aproximadamente 120 horas de conversas, durante 76 dias de interações, diálogos informais, entrevistas e participação em atividades na escola.

O Quadro 1 traz o codinome atribuído a cada jovem, sua idade e os procedimentos de recolha das narrativas de que cada um participou.

\section{QUADRO 1}

JOVENS PARTICIPANTES ${ }^{3}$ EM RELAÇÃO AOS PROCEDIMENTOS DE RECOLHA DAS NARRATIVAS

\begin{tabular}{|c|c|c|c|}
\hline \multirow[b]{2}{*}{ Identificação dos jovens } & \multicolumn{3}{|c|}{ Atividades de recolha que participaram na pesquisa } \\
\hline & $\begin{array}{l}\text { Duração das entrevistas } \\
\text { (minutos e segundos) }\end{array}$ & Conversas & Inventário \\
\hline 1. Azaleia - 19 anos & $\begin{array}{l}1^{\mathrm{a}}-30^{\prime} 38^{\prime \prime} \\
2^{\mathrm{a}}-36^{\prime} 19^{\prime \prime}\end{array}$ & Sim & Sim \\
\hline 2. Bell Marques -17 anos & $\begin{array}{l}1^{\mathrm{a}}-29^{\prime} 20^{\prime \prime} \\
2^{\mathrm{a}}-25^{\prime} 44^{\prime \prime} \\
3^{\mathrm{a}}-42^{\prime} 42^{\prime \prime}\end{array}$ & Sim & Sim \\
\hline 3. Cravo - 20 anos & $\begin{array}{l}1^{\mathrm{a}}-28^{\prime} 08^{\prime \prime} \\
2^{\mathrm{a}}-16^{\prime} 23^{\prime \prime} \\
3^{\mathrm{a}}-35^{\prime} 16^{\prime \prime}\end{array}$ & Sim & Não \\
\hline 4. Emanuel Sicômoro - 18 anos & $\begin{array}{l}1^{a}-20^{\prime} 48^{\prime \prime} \\
2^{a}-16^{\prime} 52^{\prime \prime} \\
3^{a}-09^{\prime} 03^{\prime \prime} \\
4^{a}-37^{\prime} 14^{\prime \prime}\end{array}$ & Sim & Sim \\
\hline 5. Margarida - 17 anos & $\begin{array}{l}1^{\mathrm{a}}-51^{\prime} 19^{\prime \prime} \\
2^{\mathrm{a}}-31^{\prime} 54^{\prime \prime}\end{array}$ & Sim & Não \\
\hline 6. Rosa - 18 anos & $\begin{array}{l}1^{\mathrm{a}}-37^{\prime} 29^{\prime \prime} \\
2^{\mathrm{a}}-35^{\prime} 53^{\prime \prime}\end{array}$ & Sim & Não \\
\hline 7. Violeta -18 anos & $\begin{array}{l}1^{\mathrm{a}}-37^{\prime} 51^{\prime \prime} \\
2^{\mathrm{a}}-28^{\prime} 15^{\prime \prime}\end{array}$ & Sim & Sim \\
\hline
\end{tabular}

Fonte: Elaboração dos autores. 
As narrativas constituíram canal de comunicação de sentidos e fonte de interpretação de dimensões da própria experiência de cada jovem no cotidiano. Foram analisadas a partir da proposta de Aguiar e Ozella (2013, p. 309), que consiste no estabelecimento de núcleos de significação por meio de esforço analítico em três etapas: 1) identificação de pré-indicadores: leituras das entrevistas transcritas, notas de campo e inventários buscando "palavras articuladas que [compusessem] um significado, [carregando e expressando] a totalidade do sujeito e, portanto, [constituindo] uma unidade de pensamento e linguagem", para serem transformadas em pré-indicadores; 2) construção de indicadores e conteúdos temáticos, por meio da "aglutinação dos pré-indicadores, seja pela similaridade, pela complementaridade ou pela contraposição”, diminuindo a diversidade em relação à lista anterior e, pela organização da ação, contradições e incongruências vivenciadas pelos sujeitos, resguardando a articulação e inserção desses indicadores na totalidade dos conteúdos temáticos presentes nas expressões do sujeito; 3) nomeação dos núcleos de significação: para isso, na condição de pressupostos sócio-históricos para a análise do discurso, retornamos às transcrições, aos pré-indicadores, indicadores e anotações de campo, cuidando para que os aspectos constitutivos desses núcleos e os aspectos do contexto estivessem presentes, de modo a não serem transformados em apêndices, algo com vida própria separado dos processos de significação do sujeito, presentes especialmente no material transcrito. As palavras não estão soltas na narrativa, mas integradas ao conjunto de significados que o sujeito vai imprimindo. A análise foi, portanto, um movimento cíclico, buscando um grau crescente de aprofundamento e abstração.

\section{Criação e criatividade: apontamentos a partir das narrativas}

Os elementos presentes nas narrativas possibilitaram formar um panorama relacionado à mobilização para a criatividade e ao lugar da experiência escolar nesse cenário. Esse lugar está apontado a seguir por meio de três aspectos que se integram: os elementos do conceito de criatividade que indicam a importância da experiência escolar no processo geral do seu desenvolvimento, mas não a partir diretamente do que a escola se propóe ensinar; as figuras e imagens que os jovens formavam, a partir da experiência escolar, de como a escola correspondia às suas expectativas em relação à criatividade; e as redes de espaços para criação, formadas com a participação da escola, mas com protagonismo de outros espaços e outros interesses.

\section{Criatividade: conceitos e desenvolvimento na experiência escolar}

Os sete jovens se consideravam criativos. Essa visão não apareceu relacionada ao fato de serem jovens, nem somente de conseguirem realizar algumas coisas específicas, ligadas à arte ou a um produto eventual, mas também de resolverem problemas das mais distintas ordens - pessoais, do trabalho, da escola, etc. - e requalificarem o já existente.

Três princípios marcaram essa concepção de criatividade. Um referia-se ao agir com ousadia, num sentido mais parecido com desembaraço e coragem. Algo como perceber uma situação fora daquilo que entende ser o correto e tomar uma atitude. $\mathrm{Na}$ experiência dos jovens, essa criatividade pareceu poder ser atrapalhada por questões ligadas a alguns estados emocionais que provocavam medo de errar e das críticas de terceiros, preguiça e demora em tomar decisóes. $\mathrm{O}$ excerto abaixo do jovem Bell Marques apresenta esse movimento em direção à ação e à criatividade:

... o que eu gosto de fazer é muita coisa, eu só não gosto de ficar parado, porque ficar parado é muito ruim, [gosto de assistir] seriado, ou ajudar minha mãe em alguma coisa, tocar violão, qualquer coisa eu estou fazendo, mas ficar parado não dá... Ficar parado é ficar no tédio, ficar lá sentado, olhar para parede e ver, assim, não tem nada para fazer, não tem um seriado, não tem uma música nova ... isso é o nada para mim, eu vou ler um livro, vou ler a biblia, alguma coisa, olhar alguns videos na internet. (Bell Marques, entrevista 1 ). 
Tais situações empíricas não devem ser vistas como indícios para alimentar hipóteses de uma criatividade restrita a algumas áreas, pessoas, ou estados emocionais predefinidos, positivos ou negativos, mas como reafirmação de que, sendo parte integrante do sujeito, do seu processo de desenvolvimento e envolvimento com o mundo, as caraterísticas subjetivas participantes "da expressão criativa do sujeito se constituem e se desenvolvem no decorrer de sua história de vida em função das relações que este estabelece em seus diferentes contextos sociais de ações e relações” (Mitjáns Martínez, 2002, p. 191).

Outro princípio marcante foi a noção de novidade: apresentar algo novo, mesmo que seja a partir do já existente, muitas vezes visto na convivência do dia a dia. Vincula-se a aproveitar, não desperdiçar, reciclar, transformar aquilo que era ruim - ou já utilizado - em algo especial. Esse aspecto do conceito continha a noção de que algo poderia não ser criativo, mas tornar-se, evidenciando o dinamismo dos processos de significação. Emanuel Sicômoro expressava assim sua percepção de criatividade:

. . consigo perceber imaginação e criatividade nas pessoas, nas coisas mais simples do dia a dia: quando o professor faz algo fora do comum e interage mais com os alunos, ... as faxineiras da escola, mesmo com pouco material, conseguem deixar o ambiente organizado, quando qualquer pessoa me surpreende tornando algo simples e conhecido novo aos seus olhos. (Emanuel Sicômoro, entrevista 1).

O terceiro princípio a respeito da criatividade percebido nos relatos foi a necessidade do esforço para criar, em oposição à concepção de que seria um dom ou resultante de características inatas, restritas a algumas pessoas. Criatividade surgiu como algo que se aprende e desenvolve, intensifica-se ou diminui, uma prerrogativa do humano (Vigotski, 2009) em relação direta com a própria dinâmica sócio-histórica do desenvolvimento, vinculando-se ao trabalho, à reflexividade. Azaleia relata sua caminhada em direção à criatividade como um percurso de muito esforço:

... não é que nasça, acho que a gente aprende mesmo realmente a criatividade, porque me considero sem criatividade, eu estou conseguindo agora adquirir um pouquinho graças ao RPG, que é um jogo que eu jogo que me obriga a ser criativa, entendeu? Então acho que inicialmente, não, eu não trabalhava, eu não tinha isso, era dificil, eu ficava esperando alguma coisa acontecer, tipo, ah! Tenho que resolver esta situação, mas eu ficava esperando cair do céu... não tinh a criatividade para nada, ... depois que eu comecei a trabalhar ela, já consigo resolver alguns problemas. (Azaleia, entrevista 1).

Mesmo Violeta, para quem a criatividade era entendida em parte como inata e latente - "no meu caso eu acho que veio comigo, mas eu acho que é uma coisa que vocêpode aprender, pode aprimorar, treinar" -, a ideia de aprendizado e treino aparecia em sua concepção: adormecida, poderia ser novamente despertada por esse esforço. Esforço intelectual, para questionar e produzir ideias, e físico, para executar as tarefas definidas. Isso poderia representar em alguma medida o olhar sob nova perspectiva de uma coisa qualquer, a expressão artística a sintetizar momentos vivenciados no dia a dia escolar e na vida de uma forma geral, a tomada de consciência modificando postura diante de alguma realidade, a abstração de uma dada condição já absorvida e automatizada pelo cotidiano possibilitando a crítica, a apropriação dos exemplos e modelos de terceiros colocando e retirando deles ideias além de desafios concretos para o dia a dia.

Tais princípios podem ser relacionados ao que escreve Mitjáns Martínez (1997, p. 54, itálico da autora), propondo a definição de criatividade assumida aqui: "o processo de produção de algo novo (ao menos para quem o produz) que satisfaz as exigências de uma determinada situação social”, posto que é parte do sujeito e se desenvolve com ele. $\mathrm{Na}$ experiência dos jovens, a criatividade não apareceu colocada à margem disso, mas surgiu posta em um curso do qual participavam o cognitivo e o afetivo, ou seja, o que sabiam e ia sendo dominado em termos de saber fazer era vinculado a um forte envolvimento e motivação, amor e entusiasmo relacionados à atividade realizada (Mitjáns Martínez, 1997). Elementos que, por serem constitutivos do sujeito, não podem ser considerados coisas que estariam lá antecipadamente, mas algo a ser mobilizado. 
Os jovens deram distintos exemplos, indicando uma atitude de inquietação diante do viver (Ostrower, 2001). Nesse rol estão as menções feitas por todos sobre: a organização e gestão do tempo que se tornava um desafio especialmente para os que trabalhavam; a capacidade de propor perguntas para analisar uma determinada realidade aliada à proposição de planos de ação (Emanuel Sicômoro, Rosa, Azaleia); as ações de resistência explícita a certas determinações sociais presentes na forma como a escola se relaciona com os alunos (Emanuel Sicômoro, Azaleia); os eventos cotidianos, na rua e na escola, suspendidos e transformados em poesias e crônicas (Margarida, Emanuel Sicômoro, Violeta); e a busca de algo positivo em situações adversas para superá-las (Rosa, Azaleia, Cravo, Emanuel Sicômoro, Violeta).

A apatia, sinalizada por Ostrower (2001) como sendo o oposto da ousadia e do esforço para a ação criativa, não foi observada nas narrativas. Ao contrário, a trama urdida por meio da atividade era de proposições criativas deles ao mundo. Evidentemente, mundo esse restrito à realidade concreta de cada um em seu ambiente por mais conturbado que parecesse, em um cotidiano que podia ser classificado como sendo continuamente criativo à medida que os desafiava. Vivendo e tornando-se sujeitos nos espaços instituídos por outros, esses jovens demonstraram nas histórias propor maneiras de adaptação, ainda que mínimas, desses espaços aos seus propósitos, assemelhando-se à destreza tática aludida por Certeau (1998), subvertendo o cotidiano, refazendo até o campo da desventura.

Esses três princípios marcantes da concepção de criatividade vinculam-se à ideia de superação do cotidiano (Heller, 1994) e ao grupo das atividades combinatórias (Vigotski, 2009). Aquilo que quebra a rotina instituindo o inusitado, confirmando a possibilidade empírica da criatividade em meio ao fazer diário, ajudando a dar sequência à vida, a resistir, a transformar. Quando Vigotski (2009) conclui pela relação dinâmica, dialética entre imaginação e criação, ele rompe com qualquer barreira que possa estabelecer um a priori para a manifestação da criatividade. Ainda que mortificada e entristecida pelo exílio, a prisão, a preguiça e a procrastinação, como se referiu o jovem Bell Marques, não impediriam a imaginação de funcionar, fosse a partir da intervenção na realidade concreta ou de alguma fantasia acessada por meio de histórias contadas, lidas ou assistidas nos programas televisivos ou vídeos divulgados em canais disponíveis na internet.

... escrevo às vezes, num pedaço de alguma coisa o que eu sei que vai se encaixar para fazer um poema, ou uma crônica, ou escrevo alguma coisa que aconteceu na rua, que eu sei que dá pra eu fazer, tipo, um texto, eu escrevo só essas coisas, essas bobagens . . teve outro dia que eu escrevi, ah, ... a mulher pulou a catraca no ônibus, isso é uma coisa normal, né? Ela pulou a catraca, e o grampinho do cabelo dela caiu, eu estava sentada na frente e vi, peguei e eu fui entregar a ela. O pessoal que estava atrás quando viu eu entregando achou uma coisa absurda porque era uma mulher suja e tinha pulado a catraca do ônibus, ai eu disse: moça, caiu, caiu. Eu percebi no olhar deles que achavam uma coisa nojenta. E eu que vi que era muito preconceito da parte deles. Ai eu cheguei em casa e fui escrevendo o que eu achava. Escrevi que achava que era um fator de preconceito. (Margarida, entrevista 1).

... eu sou cristão, ai quando eu vou pra igreja eu me pego pensando: porque eu vim pra igreja? Ai eu me pergunto, e se eu não fosse hoje? Ai eu não me imagino não indo pra igreja naquele dia, e também eu não me imagino não vindo um dia normal de semana pro colégio. (Bell Marques, entrevista 1).

O que me motiva a vir na escola é o futuro. Não é achar que a felicidade está no futuro, a gente tem que estar bem agora porque a gente não sabe o dia de amanhã, mas eu quero melhorar, não estou dizendo que está ruim agora, mas porque não melhorar?... eu acho que vale a pena estudar até tarde da noite, e sofrer um pouco com o sono, acordar cedo, vale tudo a pena, porque no futuro eu vou ter uma tranquilidade, olhar para atrás e dizer, nossa tudo aquilo valeu a pena. (Rosa, entrevista 2).

Os excertos acima apontam a arte e a reflexão filosófica operando este rompimento do cotidiano, claro, entendido didaticamente, traduzindo os complexos processos de apropriação e criatividade ativos 
e imbricados na cotidianidade. Rompimento experienciado nos mais distintos espaços, sendo a casa, a escola e o trabalho os que marcaram mais intensamente suas trajetórias. Traspassavam-se exercendo múltiplas interferências entre si, produzindo conhecimentos e repertórios culturais úteis para digerirem e superarem criativamente distintas situações. Tal implicação não dependia exclusivamente de uma ação coordenada por algum desses espaços, mas era feita pelo próprio jovem nos seus processos de normalização do cotidiano (Heller, 1994). Espaços adquiriam importância à medida que também se identificavam com as escolhas feitas em relação ao presente e ao futuro, mas que podiam esmaecer a depender do rumo tomado. Eram ressignificados e reposicionados a partir da experiência que ia aos poucos aumentando os repertórios culturais desses jovens e compondo sua rede para a criação.

Tal ampliação de repertórios associada à própria escolarização - processo sistemático de ensino e aprendizagem a oferecer conhecimento, algo novo, não necessariamente para a humanidade, mas para aquele particular - é capaz de desencadear processos conscientizadores e problematizadores.

Não obstante, na narrativa dos jovens sobre a escola onde estudavam, as manifestações rotineiras e eventuais de criatividade não apareceram integradas ao conteúdo, às atividades, ou à dinâmica das aulas. Os momentos de demanda e mobilização para a criação recaiam sobre alguns eventos desenvolvidos anualmente, isolados do resto, não integrados ao trabalho, mas ao calendário escolar anual: show de talentos, culminância de projetos pedagógicos e jogos esportivos internos. Tais episódios tinham um valor e despertavam o interesse dos jovens para participarem deles e da própria escola. Mas, do ponto de vista do fortalecimento da relação do estudante com a criação vinculada à prática pedagógica, funcionavam como um escape, paradoxalmente reforçando a percepção dos jovens de que faltavam à escola elementos que os fizessem enxergar a criatividade integrada à rotina escolar, à ação pedagógica. Ao mencionarem quando se perceberam criativos na trajetória de vida recente, a lembrança se dirigiu a jogos, à casa, à igreja, ao trabalho. A escola não surgiu como este espaço provocador, mas integrado aos demais a partir dos seus distintos usos definidos pelos jovens. Espaços em constelação compondo, como realidades distintas na experiência escolar de cada um, as redes para a criação.

\section{Figuras e imagens da escola: expectativas em relação à criatividade}

O espaço escolar apareceu como coadjuvante na rede onde os jovens se mobilizavam para a criatividade. Mesmo assim, era importante lugar para se viver a juventude, preparar projetos imaginados para o futuro, curtir amizades do presente. Descrito ou percebido de distintas maneiras, tanto entre os jovens como para o mesmo jovem, reforçava tanto a ideia de complexidade da escola como o fato de a atribuição de sentidos não ser uma via de mão única, mas, dada a relação entre o social e o individual, um processo dinâmico, produto das ou revelando contradições ainda não significadas, mas que indicam formas de ser (Aguiar \& Ozella, 2013).

Relaciona-se com a discussão proposta porDubet (1994,p. 130) a respeito dadesinstitucionalização: a personalidade pensa antes do papel. Uma forma de dizer que os papéis institucionais são subsumidos por aquilo que as pessoas vão fazendo da instituição ao se apropriarem dos processos, de conhecimentos, ampliando seus repertórios culturais, estabelecendo "uma lógica cultural pela qual o ator se distingue das outras lógicas", uma subjetivação que não harmoniza, mas o coloca em constante tensão com a racionalidade instrumental da ação estratégica e também com aquilo que representa a ação de integração aos valores que se institucionalizaram por meio de papéis. É nesse contexto que Pais (2016) reforça a ideia de desinstitucionalização como processo constante e indicativo de mudança social a partir das próprias instituições: vive-se, desde muito, uma reinstitucionalização permanente.

Cada escola, assim, vai assumindo um ou mais rostos, máscaras dadas a ela pelos atores sociais implicados: alunos, professores, direção, pais ou responsáveis, governos, vizinhos, etc. Nessa investigação não ocorreram conversas a respeito do objeto de pesquisa com outros atores que não os jovens. Mesmo assim, foi possível construir um quadro, preliminar que seja, da instituição a partir das imagens que os alunos demonstraram dela, na medida do que expuseram nas suas narrativas. 
Tais percepções dos jovens em relação à escola vão se transformando em figuras, imagens que às vezes se cristalizam em significados que acompanham sua trajetória, podendo sofrer alterações a partir de acontecimentos e vivências, dentro da ideia de transitoriedade e relatividade das significações que se dão a partir da subjetivação e das táticas de usos (Certeau, 1998; Dubet, 1994; Pais, 2016).

Já no último ano de uma longa jornada desta etapa da escolarização - a educação básica -, depois de pelo menos doze anos de frequência cotidiana, os jovens traziam em suas narrativas imagens da escola relacionadas a essa caminhada. Imagens não soltas ou estanques, que funcionaram como uma fotografia obtida, como se fora possível, a partir do congelamento da mais recente cena do filme da trajetória do ensino médio que chegava ao fim.

Talvez a melhor analogia seja, na verdade, a de "fotografias recortadas em jornais e folhas" como na música "Chão de Giz", de Zé Ramalho, imagens que não se formam por si, necessitando de um olhar que conecte os seus pedaços. A partir desse olhar de fora, portanto, foram percebidas com mais intensidade três imagens da escola presentes nas narrativas classificadas aqui como a imagem de uma escola monótona, a de uma escola para o uso, sempre à mão, e de uma escola para o conhecimento, atendendo ao desejo, à curiosidade de querer saber. Tais imagens conviviam umas com as outras nos discursos coletivos e individuais, não sendo, portanto, excludentes nem exclusivas, pois outros olhares poderiam juntar os pedaços dessas fotografias de outras formas... amiúde.

A figura da escola monótona dizia respeito às percepções dos jovens no que se referiam às formas de daquela unidade escolar específica dispor os seus espaços, aplicar o conteúdo das disciplinas, bem como se relacionar com o jovem quanto ao seu futuro. Essa imagem foi também significada pela expressão escola tradicional. Sem diferenciarem nos seus discursos educação, conteúdo escolar e professor, os jovens definiam como repetitiva a forma como as disciplinas eram ensinadas. Considerando estarem no último ano do ensino médio, olhavam para trás e identificavam basicamente os mesmos métodos, a mesma didática baseada no livro e no quadro, bem como conteúdos inúteis ou obsoletos. Somente ocorria algo diferente uma ou duas vezes por ano e circunscrito à execução de algum projeto educacional que tentava integrar transversalmente as disciplinas, mas acabava se concentrando mais no conteúdo de uma ou duas, como apontam os excertos abaixo.

A gente sai daqui sem saber de muita coisa, sem saber de nossos direitos, de nossos deveres ... você entra nessa sala, se você perguntar o que é a constituição, a metade não sabe, eu juro a você... onde que eu vou usar a fórmula de Bháskara? Eles estão dando valor agora a inteligência matemática. ... A gente sai da escola e acaba se achando burro, ou menos que o outro. (Azaleia, entrevista 1).

O espaço que eles dão pra gente inovar são os projetos, e projetos são feitos de seis em seis meses, então, o resto é tudo programado, já tá no plano da escola, atividades, não abre muito espaço pra você usar da sua criatividade. [Não] impedem você de ser criativo, eu diria que é mais uma ignorância, uma ignorância, não, uma falta de oportunidade ou até de motivação. (Emanuel Sicômoro, entrevista 4).

O vínculo da escola - a instituição no que se refere à sua forma, e os professores no que se refere aos métodos em geral - ao tradicional foi a imagem que prevaleceu também em relação à valorização das profissões, na indicação das carreiras a serem seguidas. Percepção que, por esse vínculo tácito entre o futuro que a escola projeta para os jovens, incentiva-os, e o status das profissões, revela uma mediação às avessas, do ideal para o material, do social como coerção sobre o individual.

Vocêpensa nas profissões que estão surgindo agora: a escola não explica, não dá um auxílio para você entender essas novas profissöes. Por exemplo, se você quer ser um designer, se você quer ser qualquer profissão que é nova no mercado, a escola não prepara você para o aprendizado dessas novidades. $O$ que ela oferece é tudo muito tradicional. Se você pensar em cursos, a escola sempre usa como exemplo cursos de engenharia, medicina, direito, cursos que estão [arraigados] na cultura das pessoas ... não consigo fazer associação entre o que eu quero e a escola. (Emanuel Sicômoro, entrevista 1). 
Tal cenário diz respeito à relação com a escola na perspectiva da estratégia (Dubet, 1994), situando-a em um mercado escolar altamente competitivo, em que se estabelecem relações de hierarquia e utilidade que reproduzem em certa medida as relações sociais.

Quanto ao espaço físico escolar, os jovens o enxergavam como múltiplo, cujos ambientes variados já eram ocupados para conversas, flertes, jogos e outras diversões. Apesar de informarem restrições operacionais - o laboratório de ciências estava desativado e o de informática subutilizado -, mencionavam também a possibilidade de sua reinvenção por parte dos professores, em oposição ao estrito uso da sala de aula: os pátios, a quadra poliesportiva, as áreas externas, etc. poderiam ser aproveitados em função do conteúdo, justificando o desabafo de Violeta na sua primeira entrevista: "a gente só faz o quê? Livro e quadro, livro e quadro. A gente quer assistir uma coisa diferente, vamos estudar história, mas assistir um filme e estudar história?".

$\mathrm{Na}$ relação com a criatividade, esta figura significada da escola aparece como algo que não atrapalha, mas também não propõe desafios. A escola não aproveita ao máximo a oportunidade de formar nos alunos uma base cada vez mais sólida para a criação ao apresentar algo que lhes era desconhecido, a novidade. Os jovens, nas suas críticas, valorizavam o conteúdo escolar, mas questionavam o processo, a forma, a ausência de uma conexão intencional mobilizando-os buscar e compreender o novo, para a criatividade.

Nessa imagem, a experiência escolar parece órfã da lógica estratégica, vinculando-se mais à integração, ao uso forçado do espaço e tempo escolar para o formal e esperado. Contudo, na condição de sujeitos, nos jovens preponderava a subjetivação. Conseguiam se afastar inclusive das relações positivamente afetivas que desenvolviam com professores, com o conteúdo em alguns casos, com o espaço escolar e com a utilidade dos estudos diante de alguns dos desafios identificados no presente, e desenvolver uma atividade crítica, como menciona Dubet (1994).

Outra figura formada a partir das imagens que os jovens proporcionaram nas narrativas é a da escola para uso, sempre à mão, prêt-á-porter, pronta para atender à necessidade do usuário. Para alguns jovens, a partir das próprias iniciativas, a relação com a escola ia sendo adequada àquilo que precisavam. À revelia da monotonia percebida, travavam um relacionamento em que aprenderam a ver e tirar pragmaticamente da escola coisas úteis para o que queriam naquele momento, reforçando uma lógica estratégica. Não expressaram outra coisa senão essa participação voltada ao consumo objetivo, refletido no uso do conteúdo escolar, seu tempo e espaço. À vista disso, a escola não compunha o eixo norteador mais forte da vida deles naquele momento. $\mathrm{O}$ trabalho, a igreja, as relações familiares eram mais inspiradores e propunham demandas aos demais espaços, incluindo a escola.

O que aconteceu ... acho que parte de ver muitas pessoas que estudavam comigo terminando e eu não, ficando para trás. ... O que me motiva a vir para a escola hoje acho que é a parte mais de aprender. Porque tem coisa aqui, tem coisas que o professor passava que eu não pensava que ia precisar, cálculos, mas como eu fiz o curso de edificações apareceram fórmulas e até cálculos que já vi aqui. Isso me ajudou bastante. Até no curso de engenharia civil vai ter muito cálculo, então essas fórmulas aqui que os professores estão passando percebi agora que não é em vão. Sei onde posso colocá-las, onde posso usá-las. (Cravo, entrevista 1).

Mesmo considerando essa perspectiva do uso da escola em função de determinadas metas, sonhos estabelecidos pelos jovens, os projetos de futuro ainda passavam pela escola, seja de uma forma bem integrada, como ocorreu com Cravo, ou de maneira mais indireta, tácita, como demonstrou Bell Marques, para quem seus vínculos com a igreja e o seu jeito de ser - não gostar de ficar parado mobilizavam sua criatividade e o direcionavam em termos de sonhos e futuro profissional. 
Como eu gosto de fazer alguma coisa, criar alguma coisa, eu gosto de engenharia, porque engenharia mexe com isso ... a escola indiretamente ajuda a ser criativo, pois mantém nossa mente ocupada, aprendendo algo novo no colégio ... nomes novos, lugares novos, [mas] eu não pratico tanto as coisas que eu recebo na escola ... só em questões de fazer uma conta ... uma pergunta sobre história eu já vou estar sabendo ... a professora de português, ensina a falar correto, a escrever correto. (Bell Marques, entrevistas 1 e 3).

Na relação com a criatividade, essa imagem pode ser vista como manifestação de uma abordagem criativa. Os jovens potencialmente vivenciam experiências criativas na escola, com ou apesar dela. Nessa figura, o fato marcante é, por assim dizer, o papel passivo da escola, representada pelo seu corpo diretivo e professores, que subsistia e não dava sinais de que fazia uma reflexão para mudança levando em consideração as questões demandadas por esses jovens e, à revelia disso, os jovens, mobilizados por diversas questões presentes nos demais espaços das suas trajetórias, pinçavam da instituição o que lhes poderia ser útil. A lógica da ação que predomina pode ser identificada como a estratégica (Dubet \& Martuccelli, 1998), resultando em uma decisão de querer "acabar bem" (Bell Marques, entrevista 1) em função do próximo passo que dariam, fosse para responder a alguma exigência do staus quo - família, grupo social, etc. -, o que representa um esforço de integração, fosse para alcançar objetivos maiores que imaginavam.

Uma terceira figura formada, seguindo as imagens apresentadas pelos jovens, foi a da escola fonte de conhecimentos presente especialmente nos discursos relacionando-a ao prazer de aprender. Alguns demonstraram pelas suas histórias verdadeiro fascínio por estarem na escola, pelo momento em si, pela experiência de ouvir o professor, acessar conhecimento novo, algo que não sabiam e acediam naqueles momentos mediados por quem ali o corporificava: o professor. A importância do conteúdo escolar perpassou todas as narrativas, mas, para duas jovens, a relação com o saber/aprender, em um dado momento, ultrapassava algu mas barreiras e se vinculava quase tautologicamente ao próprio desejo de saber/aprender.

Eu gosto de aprender... outras pessoas eu acho que não sentem isso que eu sinto, mas quando um professor está passando informações novas é tão incrivel: você está aprendendo um negócio que você nunca sabia!. . . meu Deus! Eu gosto dessa sensação de aprender . . ter assuntos para conversar com outras pessoas... falar coisas que você aprendeu, é é incrivel ter, poder compartilhar, e eu gosto disso, do que meu professor pode me dar. (Azaleia, entrevista 2).

Vir para [esta] escola é uma coisa que eu faço com prazer, [ela me] abriu portas, muitas portas. $O$ aprendizado dela não tem igual. Apesar de ser do estado, mas não tem. Eàs vezes eles sugam tanto da gente acabamos achando ruim, mas quando olhamos, "ah, era besteira". (Margarida, entrevista 1).

Na perspectiva de François Dubet, Margarida e Azaleia, apesar da origem socioeconômica simples, de não terem forte capital escolar nem dominarem perfeitamente o ofício de aluno, demonstraram nas narrativas que desenvolveram aquilo que o autor chama de "arte de converter os gostos culturais em desempenhos escolares" (Dubet, 1994, p. 213). Margarida mostrava essa habilidade mais a partir das escolhas dos livros, das conversas, da interseção dos espaços escolar e não escolar reservados à poesia e à crônica. Azaleia fazia essa demonstração pelo trânsito que realizava entre suas principais fontes de conhecimentos: a escola e os livros. Procurava enriquecer com leituras as coisas interessantes que aprendia na escola, mas também buscava, por meio das matérias escolares, aprofundar mais nos interesses despertados pelas leituras.

A criatividade aqui aparece relacionada a essa capacidade de transitar entre a estratégia e a integração, a afirmação de si mesmas como jovens, algo que passava também pelo relacionamento das duas com os professores. Nesse aspecto, as lógicas estratégicas e de integração apareciam bastante próximas na experiência escolar dessas jovens. 


\section{As redes de espaços para criação e o não protagonismo da escola}

Os jovens produziam, cada um, uma espécie de rede de espaços para a criatividade. Não como um resultado de uma ação planejada, mas como uma tática no sentido de Certeau (1998), na maneira de usar, de se posicionar nos lugares sobre os quais não tinham autoridade. Por esse motivo, como propõe o autor, esses lugares eram utilizados como espaços, que acabavam se conformando em rotas de fuga, onde cumpriam as normas de cada um, mas sempre encontrando maneiras não autorizadas, não previstas ou mesmo não esperadas de uso.

Como já mencionado, os jovens se viam criativos e envolvidos em processos de criação, conseguindo identificar estes vínculos e os produtos da sua criatividade no seu cotidiano. Esse movimento era mobilizado por distintos espaços, inclusive o escolar, fornecendo a eles o contato direto, aberto com diferenciados conhecimentos, passando a funcionar na forma de um suporte à criatividade. A partir de mediações e mecanismos que os jovens iam provendo ou lançando mão, os conteúdos escolares e não escolares iam se integrando.

Em alguns casos, principalmente nas narrativas de Emanuel Sicômoro e Margarida, a rua dava ideias para as poesias. Por sua vez, conseguiam enxergar, na disciplina de português, recursos para a estrutura e as palavras do texto. Dos livros lidos e dos programas televisivos assistidos outros elementos eram obtidos para essas produções textuais e, em um movimento reverso, o desafio de encontrar soluções gramaticais criativas para as produções literárias os levava de volta à disciplina de português, cujo estudo se tornava um privilégio.

Esta poesia também está relacionada com a escola diretamente, um assunto que discutíamos na aula de história: as passeatas relacionadas ao impeachment da presidente Dilma. .. . O que mais me motiva a escrever poesias é o fato de entender que éuma bo forma de exercitar a criatividade ao ter que achar soluçôes para cada verso ... soluçôes inovadoras na escrita. (Emanuel Sicômoro, entrevista 4).

Eu acho que é porque todos os dias a gente aprende na escola, e eu acho que uma das motivações que eu tenho para vir a escola. . . é a aula de português [estudar] português sempre foi um privilégio pra mim, sempre foi ... pela professora e pelo que escrevo... Minh a criatividade: escrever, escrever. (Margarida, entrevista 2).

Em outros casos, como Cravo, os cálculos matemáticos demandados no novo ambiente de formação profissionalizante e no trabalho eram os mesmos constantes do conteúdo daquele momento da disciplina de matemática, o que provocava a integração dos respectivos espaços, que se valorizavam mutuamente, e o novo olhar sobre aquele antigo conteúdo que se tornara novo aos seus olhos.

Formavam-se redes de espaços para a criação em que distintos saberes eram mobilizados e integrados às necessidades cotidianas, mas não somente a partir da escola. Apesar da multiplicidade de figuras pelas quais a escola apareceu significada nos discursos desses jovens, nenhuma delas a colocava como protagonista nessas redes. Não percebiam nenhum movimento, seja a partir do planejamento dos professores ou do corpo diretivo, que integrasse saberes e espaços transitados e ocupados por eles em função da sua especificidade como escola. Somente os eventos, como já mencionado, eram inseridos no calendário anual escolar, criando um interregno, para depois retomar o curso mais frequentemente identificado como monótono.

Nem mesmo a sua intervenção, o seu papel mais vinculado ao fornecimento de conteúdo importante para a formação intelectual do aluno, aspecto valorizado pelos jovens da pesquisa, na medida em que a escola deve ser vista como tendo algo específico para os alunos, o que faz parte da sua própria razão de ser e da própria escolarização, foi uma imagem que se sobrepôs em relação às demais.

As redes de espaços para a criação, portanto, eram construídas e dinamizadas principalmente a partir da mobilização dos outros espaços frequentados pelos jovens (igreja, trabalho remunerado, casa e a rua) e das coisas que gostavam e sentiam prazer em fazer, funcionando como propositores e expansores dos repertórios culturais e de conhecimento desses jovens para o exercício da criatividade, na expressão 
juvenil de cada um e na tomada de decisões. Nessa dinâmica, a escola tinha sua importância relacionada à multiplicidade do que podia fornecer: o espaço para as amizades e amores, o acolhimento, aprendizado em função do passar de ano, do Enem (Exame Nacional do Ensino Médio), bem como do prazer de aprender.

A integração de espaços em favor da criação tinha como ponto de partida o diálogo buscado entre suas experiências como jovens que eram também estudantes, com uma determinada condição sócio-histórica, e os saberes escolares fortalecendo a própria presença da escola como parte da rede. A ação dos jovens, portanto, é que a fortalecia, pois não era percebida com papel ativo na promoção da criatividade, algo que fosse além da importância tácita: oferecer uma base de conhecimento, parte daquilo que vem sendo historicamente acumulado pela humanidade.

As redes indicavam uma capacidade desses jovens de organizar a agenda diária, de lidar com algumas pressões impostas pela condição de cada um. Não simbolizavam a vitória sobre a realidade às vezes sufocante e adoecedora, ou sucesso ou insucesso no que diz respeito aos tipos de ação vinculados às expressões criativas. Esses jovens lançavam mão de ações criativas no emaranhado de rotas formado, como se não quisessem perder o sentido das coisas que faziam e dando à escola um sentido de correspondência com o presente pelas distintas conexões que iam sendo feitas nas suas trajetórias.

Tais redes ainda, vistas como resultado do processo de subjetivação, estabeleciam uma tensão, pois, assim que o sujeito adota postura crítica e ativa diante da realidade, não a experimenta mais harmônica e completamente, mas sim "como uma tensão com as outras lógicas de ação. A ética de convicção, fora da figura heroica do profeta, define-se em primeiro lugar na sua tensão com a racionalidade instrumental, ou com a moral comunitária" (Dubet, 1994, p. 130). O sujeito, então, estabelece um compromisso consigo mesmo e vai construindo sua identidade pela tensão com o mundo, representado pelas ações de integração e estratégia. Compromisso "vivido como um inacabamento, como uma paixão impossível e desejada que permite descobrir-se como autor da sua própria vida, ainda que seja na amargura ocasionada pela impossibilidade de realizar plenamente esse projeto" (Dubet, 1994, p. 131).

Em contraponto, analisando a situação juvenil e os processos socializadores nos espaços intersticiais das instituições, Machado Pais reflete sobre o isolamento do sistema de ensino que, alheio à realidade que o rodeia, funciona quase como algo autônomo do resto. Para o autor, esse procedimento parece ser legitimado pela ideia de tal sistema referir-se ao futuro posto ao jovem como meta para formação de "futuros cidadãos, pais de família, profissionais, líderes, dirigentes [como] seres em trânsito, sem presente, adultos potenciais em futuro" (Pais, 2016, p. 297), reforçando a ideia de recompensa adiada, futurizando equivocadamente o presente e focando no mercado de trabalho (Dayrell \& Jesus, 2016). Contudo, as redes de espaços para a criação pareceram representar possibilidades de melhor vincular, naquele momento, a escola ao presente dos jovens.

\section{Considerações finais}

Retomando a questão inicial, algumas considerações podem ser feitas sobre a relação entre a juventude, criatividade no cotidiano e experiência escolar. No que diz respeito à rede de relações construídas, as narrativas apontam jovens atravessados - frequentando, influenciando e sendo influenciados - por múltiplos espaços e interesses. A escola era um desses onde ser/tornar-se aluno era uma das questões. Ela emergiu das narrativas como algo importante, ainda que com intensidade variada para cada jovem, mas não protagonista para os processos de criação nem no movimento de significação desses outros espaços. Pelo contrário, na experiência escolar, a relação com a escola era mediada por eles.

Para Dayrell (2007), o jovem vive as diversas dimensões da sua condição juvenil em espaços por ele significados. A experiência dos jovens entrevistados aponta uma relação paradoxal entre o sentido vivenciado e a forma pragmática como a escola é social e hegemonicamente imposta, na trilha do que se considera uma sociedade escolarizada. Sinaliza perda de monopólio da escola no que tange à referência para a experiência juvenil. 
Seus sonhos de futuro, no curto e médio prazo, por exemplo, estavam imbricados na rede estabelecida. Em certa medida, passavam pela escola cujo papel se dava mais no nível da tática (Certeau, 1998), desvelando-se principalmente no desejo de entrada no ensino superior, fornecendo conhecimentos estruturados pelos quais poderiam superar os testes de acesso. No presente daqueles jovens, a escola exercia esse papel coadjuvante de fornecer ferramentas úteis, preparatórias, no processo de integração dos espaços operada pelos jovens.

A criatividade apareceu como algo possível no cotidiano, reconhecida pelos jovens a partir de múltiplas manifestações, tanto pelo produto advindo do processo como pelas maneiras de estarem e se colocarem no desenvolvimento dessas ações. A realidade narrada apresentou uma criatividade expressa em distintos lugares, momentos e por pessoas distintas, coadunando o preconizado por Certeau (1998), Ostrower (2001) e ainda Vigotski (2009), confirmando, nesse contexto, a impossibilidade prática de restringir o trânsito do agir criativamente e da produção criativa. As ações criativas compartilhadas se deram em situações de distintas emoções - tristeza, alegria, medo, frustrações, esperança - e com distintos propósitos - a sobrevivência da família, a assimilação de conteúdos escolares, a subversão do uso de espaços, a realização de momentos de lazer, a produção artística, a mobilização de pessoas, de recursos financeiros, o descanso e a reflexão.

Como dito, essas ações criativas ocorreram em um trânsito sem restrições entre os espaços que compunham as redes que se formaram, estabelecendo-se no cotidiano, tornando-se parte dele. Por óbvio, o cotidiano desses jovens estava bastante impregnado de escola, das tarefas escolares, do fim de ano escolar, das notas para passarem de ano, da festa de conclusão, da preparação para as provas de acesso ao ensino superior. A rede de espaços para criação estabelecida, as ações criativas, tanto as mais eventuais como as mais escondidas em meio à rotina cotidiana, vinculavam-se à experiência escolar. Uma experiência construída a favor de si mesmos, procurando servir-se da escola na medida da necessidade e da utilidade para os planos estabelecidos numa lógica da ação mais estratégica.

A criatividade, ainda que não possa aparecer sem o exercício da imaginação, não resulta necessariamente em produto criativo, posto que barreiras podem se colocar entre a imaginação e a sua realização. Para o jovem, portanto, além do ambiente diversificado, da proposta de atividades que demandem mais imaginação e mais criatividade para solucioná-las, é necessário valorização do protagonismo, compreensão de que, além do desenvolvimento biológico, o jovem adquire poder - seja pela ação própria de empoderar-se, seja fruto de uma divisão por parte dos outros - que se desdobra, entre outras coisas, na capacidade e/ou oportunidade de escolha, de criar e de lidar direta e responsavelmente com as consequências.

Nesse aspecto, a gestão do tempo tornou-se algo importante na medida em que estudar e fazer atividades relacionadas ao trabalho, à diversão e ao lazer exigia um grande esforço de organização da agenda cotidiana. Talvez estivesse nisso - a relação com o tempo - o que havia de mais criativo entre esses jovens: faziam tantas coisas e ainda tão jovens administravam praticamente sozinhos, por sua conta e risco, seus tempos e atribuições.

\section{Referências}

Aguiar, W. M. J., \& Ozella, S. (2013). Apreensão dos sentidos: Aprimorando a proposta dos núcleos de significação. Revista Brasileira de Estudos Pedagógicos, 94(236), 299-322.

Biarnès, J. (2007). Education, diversité et espaces de création à l'école. Revista Moçambrás, 1(2). https://www. redalyc.org/pdf/879/87910204.pdf

Certeau, M. de. (1998). A invenção do cotidiano: Artes de fazer. Vozes.

Constituição da República Federativa do Brasil de 1988 (1988). Brasília. http://www.planalto.gov.br/ccivil_03/ constituicao/constituicao.htm 
Dallabrida, N. (2004). Nascimento da escolarização moderna. Perspectiva, 22(1), 93-110.

Dayrell, J. T. (2007). A escola "faz" as juventudes? Reflexões em torno da socialização juvenil. Educação e Sociedade, 28(100), 1105-1128. http://www.scielo.br/scielo.php?script=sci_arttext\&pid=S0101$73302007000300022 \& \operatorname{lng}=$ pt\&nrm=iso

Dayrell, J. T., \& Jesus, R. E. (2016). Juventude, ensino médio e os processos de exclusão escolar. Educação e Sociedade, 37(135), 407-423.

Dubet, F. (1994). Sociologia da experiência. Instituto Piaget.

Dubet, F., \& Martuccelli, D. (1997). A socialização e a formação escolar. Lua Nova, 40-41, 241-266.

Dubet, F., \& Martuccelli, D. (1998). En el colégio. In F. Dubet, \& D. Martuccelli, En la escuela: Sociologia de la experiencia escolar (pp. 185-312). Editorial Losada.

Ezpeleta, J., \& Rockwell, E. (1989). Pesquisa participante. Cortez; Autores Associados.

Heller, A. (1994). Sociología de la vida cotidiana. Ediciones Península.

Instituto Brasileiro de Geografia e Estatística. (s.d.). Sistema IBGE de Recuperação Automática. https://sidra. ibge.gov.br/tabela/7215\# resultado.

Leão, G. (2018). O que os jovens podem esperar da reforma do ensino médio brasileiro? Educação em Revista, 34, 1-23.

Leão, G., \& Carmo, H. C. do. (2014). Os jovens e a escola. In L. M. Correa, M. Z. Alves, \& C. L. Maia (Orgs.), Cadernos temáticos: Juventude brasileira e ensino médio (pp. 11-44). Editora UFMG.

Lei n. 12.852, de 05 de agosto de 2013. (2013). Institui o Estatuto da Juventude e dispóe sobre os direitos dos jovens, os princípios e diretrizes das políticas públicas de juventude e o Sistema Nacional de Juventude - SINAJUVE.http://www.planalto.gov.br/ccivil_03/_ato2011-2014/2013/lei/l12852.htm

Mitjáns Martínez, A. (1997). Criatividade, personalidade e educação. Papirus.

Mitjáns Martínez, A. (2002). A criatividade na escola: Três direções de trabalho. Linhas Críticas, 8(15), 189-206.

Molon, S. I. (2008). Questões metodológicas de pesquisa na abordagem sócio-histórica. Informática na Educação: Teoria \& Prática, 11(1), 56-68.

Ostrower, F. (2001). Criatividade e processos de criação. Vozes.

Pais, J. M. (2016). Ganchos, tachos e biscates: Jovens, trabalho e futuro. Edições Machado.

Sposito, M. P. (2003). Uma perspectiva não escolar no estudo sociológico da escola. Revista USP, 57, 210-226.

Veloso, A. de M. (2010). Um espaço criativo e seu impacto na subjetividade: Um estudo com alunos calouros [Mestrado em Educação]. Universidade de Brasília, Brasília.

Vigotski, L. S. (2009). Imaginação e criação na infância. Ática.

\section{Nota sobre autoria}

Os autores participaram igualmente na elaboração e revisão do artigo.

\section{Disponibilidade de dados}

Os dados subjacentes ao texto da pesquisa estão informados no artigo.

\section{Como citar este artigo}

Trancoso, A. E. R., \& Reis, R. (2021). Criatividade no cotidiano de jovens: O lugar da escola e da experiência. Cadernos de Pesquisa, 51, Artigo e07308. https://doi.org/10.1590/198053147308 